\title{
Knowledge of Nurses toward Prevention for Catheter-Associated Urinary Tract Infection in Public Hospitals at Amran City, Yemen
}

\author{
Abdulnasser A. Haza'a* (1), Abdulfatah Al-Jaradi, Marzoq Ali Odhah \\ Critical Care and Emergency Nursing, Faculty of Medical Sciences, Al-Razi University, Sana'a, Yemen \\ Email: `jaamha2008@gmail.com, alfatah711183371@gmail.com, abu.ali551@gmail.com
}

How to cite this paper: Haza'a, A.A., Al-Jaradi, A. and Odhah, M.A. (2021) Knowledge of Nurses toward Prevention for Catheter-Associated Urinary Tract Infection in Public Hospitals at Amran City, Yemen. Open Journal of Nursing, 11, 933-946. https://doi.org/10.4236/ojn.2021.1111076

Received: October 2, 2021

Accepted: November 13, 2021

Published: November 16, 2021

Copyright $\odot 2021$ by author(s) and Scientific Research Publishing Inc. This work is licensed under the Creative Commons Attribution International License (CC BY 4.0).

http://creativecommons.org/licenses/by/4.0/

\begin{abstract}
Background of the study: Catheter-associated urinary tract infection (CAUTI) is the most prevalent healthcare-associated infection worldwide, according to reports. Nurses are also accountable to acquire appropriate knowledge and practices of catheter care that will prevent UTI. Nurses' knowledge is seen to be one of the most important factors in their practice. Aim of the study: To assess the nurse's knowledge toward the prevention of catheter-associated urinary tract infection in public hospitals at Amran City. Methods: A descriptive cross-sectional study was conducted among nurses at public hospitals in Amran City, Yemen. A convenience sampling technique was of the study consisted of 93 nurses from different public hospitals that were participated in this study. Self-administered questionnaire was used to collect data from March 2021 to April 2021. Results: The distribution of nurses' ware female $65.6 \%$, belonged to age group between ( 25 to $<30$ years) $43.0 \%$. The Diploma degree was the most available qualification $88.2 \%, 81.7 \%$ between 1 - 5 years' experience as nurses. Knowledge regarding prevention of catheter-associated urinary tract infection was fair $72 \%$, while $18.3 \%$ had a good. There is a significant statistical difference between knowledge level regarding prevention of CAUTI, and sex $(\mathrm{P}-\mathrm{value}=0.042)$. Conclusion: Most of nurses had fair knowledge level regarding prevention of catheter-associated urinary tract infection. Recommendations: We recommended increasing the knowledge of nursing staff through the courses training, workshop, and curriculums.
\end{abstract}

\section{Keywords}

Knowledge, Nurses, Prevention, Catheter, Urinary Tract Infection 


\section{Introduction}

CAUTI is a Urinary Tract Infection (UTI) in a patient with a catheter present or within 48 hours of catheter removal. Prolonged catheterization is a risk factor for developing a CAUTI [1]. UTI is a common infection among health care settings. Urinary catheter insertion is considered the most important predisposing factor for CAUTI and almost $25 \%$ of them undergo urinary catheterization during their stay in the hospital [2] [3]. The most common hospital-acquired infection is CAUTI accounting for almost $40 \%$ of all nosocomial infections [4] [5]. Nurses are considered as the primary health care providers who are responsible for inserting and maintain urinary catheters, as well as the production of desired outcomes. Nurses are also accountable to acquire appropriate knowledge and practices of catheter care that will prevent UTI [2].

\section{Problem Statement}

The global burden of Hospital-Acquired Infection (HAI) is underestimated in developing countries due to lack of surveillance systems, The Association for Professionals in Infection Control and Epidemiology in the United States also reported that CAUTI is accounting for $25.6 \%$ of all HAIs [2]. CAUTI remains an expensive complication, though the additional cost to a hospitalization varies by assessment method from a few hundred dollars to thousands of dollars [6]. The National Healthcare Safety Network in 2013 reported that CAUTI pooled means were ranged from 1.2 to 4.1 per 1000 urinary catheter days in medical-surgical and burn intensive care units. While for Non-ICU rates ranged from 1.3 to 1.5 per 1000 urinary catheter days in medical-surgical units [3]. CAUTI can lead to such complications as prostatitis, epididymitis, and orchitis in males, and cystitis, pyelonephritis, gram-negative bacteremia, endocarditis, vertebral osteomyelitis, septic arthritis, endophthalmitis, and meningitis in patients. Complications associated with CAUTI cause discomfort to the patient, prolonged hospital stay, and increased cost and mortality. It has been estimated that each year, more than 13,000 deaths are associated with UTIs [7].

\section{Significance of the Study}

The significance of this study, from a researcher it will provide baseline information on nurses' knowledge level and practice on prevention of CAUTI. Health care professionals must be skillful and competent enough with their knowledge and skills to prevent UTI among the hospitalized patient under indwelling catheter and give adequate knowledge to patients regarding the prevention of CAUTI [2]. Therefore, this study aimed to assess the nurse's knowledge toward the prevention of catheter-associated urinary tract infection in public hospitals at Amran City.

\section{Research Questions}

1) Do nurses have knowledge about prevention of CAUTI? 
2) What is the relationship between demographic characteristics of nurses and their knowledge level regarding about prevention of CAUTI?

\section{Methods}

\subsection{Study Design}

A descriptive, cross-sectional study was carried out to assess the nurse's knowledge toward the prevention of catheter-associated urinary tract infection.

\subsection{Study Setting}

The study was conducted from March to April 2021 in four public hospitals in Amran City-Yemen. That include are 22 May Central Teaching hospital, Maternal and Child Hospital, National Consultant Hospital and AL-Makhathi Hospital, those hospitals are referral for the most population in the region that were chosen by purposive sampling technique, which has (Emergency department \& Intensive care units).

\subsection{Sample Size Determination}

Due to the relatively large population of potential participants, and time restraint the researchers were considered to select sample size from all populations that were invited to participate in this study. The sample size was determined through the use EpiCalc program version 2000, taking into consideration the following (total of population 389, the precision level (4\%), and the confidence level (95\%). The final was selected for sample size of 93 nurses.

\subsection{Sampling Technique}

Purposive sampling technique was applied to select the sample size from four public hospitals, after official approvals obtained from the previously selected settings. All emergency and ICU nurses who had at one year working experience, including both males and females with different educational qualifications, who were involved directly in emergency and ICU patients care, full-time employees and had agreed to participate were eligible to take part in this study.

\subsection{Inclusion and Exclusion Criteria}

\subsubsection{The Inclusion Criteria Were Included}

1) All nurses who have direct contact with patients in the previous settings in with various education levels.

2) All nurses who had a duration of working about 1 year and more.

\subsubsection{The Exclusion Criteria Were Included}

- All Nurses who are not fulfilling the above inclusion criteria.

\subsection{Data Collection Tool}

Based on a comprehensive review of the previous related studies, a self-administered questionnaire was developed by the researchers. The questionnaire is 
divided into two sections as follow:

Section one: the socio-demographic characteristics of the participants: age, sex, level of education, years of experience, and level of education, department work, and training courses on prevention of catheter-associated urinary tract infection.

Section two: knowledge of nurses toward prevention of catheter-associated urinary tract infection. The questionnaire consists of 22 questions.

\subsection{Scoring System}

The researchers were classifying the level of knowledge as follows: level percentages good knowledge 76\% - 100\%, fair knowledge 50\% - 75\% and poor knowledge $0 \%-49 \%$. Each correct response to the items in the questionnaire were given ( 1 score), and (0 scores) was given to either wrong response. The total score of knowledge is 22 scores.

\subsection{Validity and Reliability of the Tool}

The validity of the English version of the questionnaire was reviewed by three experts to determine if all questions were wording and word is not misinterpreting. Experts included only nursing staff as a result, some questions were omitting, some adding and others rephrasing. Other questions adding was formulated by the researcher with the help of the literature supervisor and experts was make modifying to add or omit to clearly and correct misinterpreted and doubtlessness from credence and completeness of study tool. The reliability of the questionnaire was testing by using (Cronbach's Alpha $=0.60$ ).

\subsection{Pilot Study}

The piloted questionnaire was performed before data collection. A pilot study was done on ten working nurses on items in a questionnaire to assess the clarity, feasibility of the study, and drawbacks of the questionnaire. Following the pilot study, minimal modifications to the layout and presentation of the instrument were made. The pretest nurses were excluded from the final study sample.

\subsection{Data Collection}

A self-administered questionnaire was distributed during the period of March to April 2021. The nurses in the selected hospitals were invited to fill the questionnaire.

\subsection{Ethical Considerations}

Approval of the study was obtained before carrying out this study from the faculty of medical sciences, Al-Razi University. A cover letter was sent to the principles of hospitals to obtain approval to conduct this study. The purpose and benefits of the study were explaining to participants. The consent was taken from all participating nurses in the study. All nurses also have the right to refuse 
to participate or to withdraw from the study without any effect on their work.

\subsection{Data Processing and Statistical Analysis}

Once the questionnaires were collected, a codebook was developed to provide numerical results for analysis. A packaged computer analysis program, statistical package for the social science (SPSS 22.0) was used for statistical analysis of this data. Descriptive statistics were used to interpret the demographic data: age, sex, working experiences, and training. Descriptive measures, including frequency, the percentage for categorical variables, and the mean and standard deviation for numerical variables. To find the association between knowledge and demographic characteristics was used chi-square test for categorical data, and P-value $\leq$ of 0.05 was considered significant.

\section{Results}

Table 1 shows the demographic characteristics of the ICU nurses, the most (65.6\%) of nurses were female belonged age group between 25 to $<30$ years old (43.0\%), and more than half (51.6\%) of them were single, followed by the majority of nurses $(88.2 \%)$ were had diploma degree on belonged experience years between ( $1-5$ years) $81.7 \%$. Whereas, slightly more than half (51\%) of them were had training courses in the prevention catheter-associated urinary tract infection.

Table 2 showed the vast majority of nurses (97\%) were knew that antimicrobial prophylaxis offers are not greater benefit in reducing the incidence of CAUTI, followed by the majority (90\%) of nurses knew that antiseptic meatal

Table 1. Demographical characteristics of nurses.

\begin{tabular}{|c|c|c|c|}
\hline Demographical characteristics & Categories & Number $(N)$ & Percent (\%) \\
\hline \multirow{3}{*}{ Age group } & $20-<25$ years & 38 & 40.9 \\
\hline & $25-<30$ years & 40 & 43.0 \\
\hline & $\geq 30$ years & 15 & 16.1 \\
\hline \multirow{2}{*}{ Sex } & Male & 32 & 34.4 \\
\hline & Female & 61 & 65.6 \\
\hline \multirow{2}{*}{ Marital Status } & Single & 48 & 51.6 \\
\hline & Married & 45 & 48.4 \\
\hline \multirow{2}{*}{ Education Level } & Diploma degree & 82 & 88.2 \\
\hline & Bachelor's degree & 11 & 11.8 \\
\hline \multirow{3}{*}{ Years of Experience } & $1-5$ years & 76 & 81.7 \\
\hline & $6-10$ years & 13 & 14.0 \\
\hline & $11-15$ years & 4 & 4.3 \\
\hline \multirow{2}{*}{$\begin{array}{l}\text { Training courses in the } \\
\text { prevention of CAUTI }\end{array}$} & Yes & 47 & 51 \\
\hline & No & 46 & 49 \\
\hline
\end{tabular}


Table 2. Distribution of Nurse's knowledge regarding preventive of CAUTI.

\begin{tabular}{|c|c|c|c|c|}
\hline \multirow{2}{*}{ Item } & \multicolumn{2}{|c|}{ Correct answer } & \multicolumn{2}{|c|}{$\begin{array}{l}\text { Incorrect } \\
\text { answer }\end{array}$} \\
\hline & $\operatorname{Number}(N)$ & Percent $(\%)$ & $\operatorname{Number}(N)$ & Percent (\%) \\
\hline $\begin{array}{l}\text { 1) Antimicrobial prophylaxis offers greater benefit in reducing the } \\
\text { incidence of CAUTI. }\end{array}$ & 90 & 97 & 3 & 3 \\
\hline $\begin{array}{l}\text { 2) Prophylactic antimicrobials should be given for } 3 \text { days when the } \\
\text { catheter is inserted. }\end{array}$ & 25 & 27 & 68 & 73 \\
\hline $\begin{array}{l}\text { 3) Using alcohol hand sanitizer is comparable to hand washing in } \\
\text { preventing CAUTI incidence. }\end{array}$ & 16 & 17 & 77 & 83 \\
\hline $\begin{array}{l}\text { 4) Routine use of antiseptic lubricants to decrease the risk of infection is } \\
\text { necessary for urinary catheter insertion. }\end{array}$ & 12 & 13 & 81 & 87 \\
\hline $\begin{array}{l}\text { 5) Silicone is preferable to Teflon-coated and latex catheter materials in } \\
\text { reducing the risk of encrustation for long-term catheterized patients who } \\
\text { have frequent obstruction. }\end{array}$ & 82 & 88 & 11 & 12 \\
\hline $\begin{array}{l}\text { 6) Antiseptic meatal cleaning before catheter insertion is necessary for } \\
\text { reducing the incidence of catheter-associated urinary tract infection. }\end{array}$ & 84 & 90 & 9 & 10 \\
\hline 7) Removing catheters as early as possible. & 79 & 85 & 14 & 15 \\
\hline $\begin{array}{l}\text { 8) Effective use of Amikacin Sulfate bladder washes as prophylaxis before } \\
\text { catheter removal. }\end{array}$ & 34 & 37 & 59 & 63 \\
\hline $\begin{array}{l}\text { 9) Hand washing should be done immediately before and after any } \\
\text { manipulation of the catheter site or apparatus. }\end{array}$ & 81 & 87 & 12 & 13 \\
\hline $\begin{array}{l}\text { 10) As small a catheter as possible should be used to minimize urethral } \\
\text { trauma. }\end{array}$ & 76 & 82 & 17 & 18 \\
\hline $\begin{array}{l}\text { 11) It should be inserted only when necessary and removed as soon as } \\
\text { possible. }\end{array}$ & 79 & 85 & 14 & 15 \\
\hline $\begin{array}{l}\text { 12) Use of other methods of urinary drainage such as condom catheter } \\
\text { drainage, suprapubic or intermittent catheterization for selected patients. }\end{array}$ & 71 & 76 & 22 & 24 \\
\hline $\begin{array}{l}\text { 13) Avoid kinking of the catheter to maintain an unobstructed flow of } \\
\text { urine. }\end{array}$ & 79 & 85 & 14 & 15 \\
\hline $\begin{array}{l}\text { 14) Irrigation of the bladder with antimicrobial solution/iodine solution } \\
\text { at least once daily. }\end{array}$ & 45 & 48 & 48 & 52 \\
\hline 15) Twice daily meatal care with an antiseptic solution. & 18 & 19 & 75 & 81 \\
\hline 16) The collecting bag should be emptied regularly. & 83 & 89 & 10 & 11 \\
\hline 17) The collecting bag should be kept below the level of the bladder. & 84 & 90 & 9 & 10 \\
\hline 18) Regular bacteriological monitoring of catheterized patients. & 74 & 80 & 19 & 20 \\
\hline $\begin{array}{l}\text { 19) The catheter should be inserted only by personnel proficient in the } \\
\text { technique of aseptic insertion. }\end{array}$ & 75 & 81 & 18 & 19 \\
\hline $\begin{array}{l}\text { 20) Isolation of patients known to have UTI from other non-infected } \\
\text { patients. }\end{array}$ & 31 & 33 & 62 & 67 \\
\hline 21) Regular educational training regarding basic urinary catheter care. & 84 & 90 & 9 & 10 \\
\hline 22) Routinely using antimicrobial coated catheters. & 16 & 17 & 77 & 83 \\
\hline
\end{tabular}


cleaning before catheter insertion is necessary for reducing the incidence of catheter-associated urinary tract infection, collecting bag should be kept below the level of the bladder, and Regular educational training regarding basic urinary catheter care is from preventive measures of CAUTI. While only (13\%) of nurses knew that routine use of antiseptic lubricants to decrease the risk of infection is necessary for urinary catheter insertion don't from preventive measures of CAUTI.

Figure 1 showed that, more than two third of nurses had moderate knowledge regarding prevention of CAUTI (72\%), (18.3\%) of nurses were had good knowledge regarding prevention of CAUTI. Whereas only $(9.7 \%)$ of nurses had poor knowledge regarding prevention of CAUTI with mean \pm SD $(14.17 \pm 2.51)$.

Figure 1 showed that, more than two third $(72 \%)$ of nurses had fair knowledge level, (18.3\%) of nurses were had good knowledge level regarding prevention of CAUTI. Whereas only (9.7\%) of nurses had poor knowledge level regarding prevention of CAUTI with mean \pm SD $(14.17 \pm 2.51)$.

Table 3 showed a significant association between knowledge level regarding preventive of CAUTI, and demographic characteristics of nurses regarding sex at (P-value $=0.042)$. No statistically significant association between overall knowledge and other demographic characteristics of nurses ( $\mathrm{P}$-value $\geq 0.05$ ).

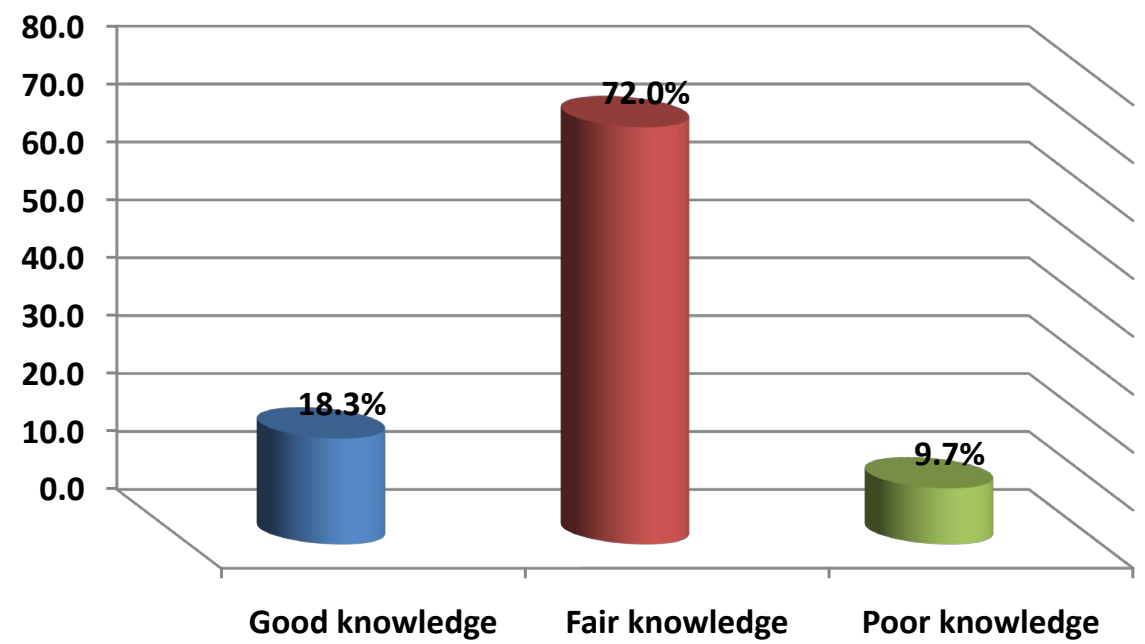

Figure 1. Distribution of nurses' knowledge level regarding prevention of CAUTI.

Table 3. Association between the demographical characteristics of nurses and knowledge level.

\begin{tabular}{|c|c|c|c|c|c|}
\hline \multirow[b]{2}{*}{$\begin{array}{l}\text { Demographical } \\
\text { characteristics }\end{array}$} & \multirow[b]{2}{*}{ Categories } & \multicolumn{4}{|c|}{ Knowledge level } \\
\hline & & \multicolumn{3}{|c|}{ Knowledge Knowledge Knowledge P-Value } & $P$-value \\
\hline \multirow{3}{*}{ Age group } & $20-<25$ years & 6 & 28 & 4 & \\
\hline & $25-<30$ years & 7 & 29 & 4 & 0.915 \\
\hline & $\geq 30$ years & 4 & 10 & 1 & \\
\hline
\end{tabular}


Continued

\begin{tabular}{|c|c|c|c|c|c|}
\hline \multirow{2}{*}{ Sex } & Male & 11 & 20 & 3 & \multirow{2}{*}{0.042} \\
\hline & Female & 8 & 44 & 14 & \\
\hline \multirow{2}{*}{ Marital status } & Single & 9 & 31 & 12 & \multirow{2}{*}{0.311} \\
\hline & Married & 10 & 33 & 5 & \\
\hline \multirow{2}{*}{ Education level } & Diploma degree & 15 & 58 & 14 & \multirow{2}{*}{0.514} \\
\hline & Bachelor's degree & 3 & 4 & 2 & \\
\hline \multirow{3}{*}{ Years of experience } & $1-5$ years & 13 & 56 & 7 & \multirow{3}{*}{0.845} \\
\hline & $6-10$ years & 3 & 8 & 2 & \\
\hline & $11-15$ years & 1 & 3 & 0 & \\
\hline \multirow{2}{*}{$\begin{array}{l}\text { Training courses in the } \\
\text { prevention of CAUTI }\end{array}$} & Yes & 9 & 32 & 10 & \multirow{2}{*}{0.861} \\
\hline & No & 10 & 32 & 8 & \\
\hline
\end{tabular}

\section{Discussion}

One of the most prevalent health-care-associated infections is CAUTI. One of the causes is that urinary catheters that have been placed in hospitalized patients stay in place long after the rationale for their usage has expired. The most essential preventative approach in reducing the occurrence of CAUTI is to limit catheter usage. Assessing health care professionals' knowledge of catheterization and UTI, particularly nurses' knowledge, would aid in the management of problems linked to CAUTI and improper catheterization [2]. The aim of this study was to assess the knowledge levels of nurses toward the prevention of catheter-associated urinary tract infection at major hospitals in Amran City Yemen.

The results of this study were based on the primary data gathered from ninety-three nurses to assess the knowledge. The prevention of CAUTI is primarily the responsibility of the nurse whose knowledge and practice influence the health outcome of patients. Nurses are considered as the primary health care providers who are responsible for inserting and maintain urinary catheters, as well as the production of desired outcomes.

Our study result, two thirds of nurses were female, and more than half of them were single, belonged on the age group between 20 to less than 25 years old (40.9\%). Because most of the old nursing quit work and went to other hospitals because government hospitals do not have salaries in them, and this is because of the wars in our country. The majority of nurses were had diploma degree and had years' experience group between one to five years. The half of nurses (51\%) had training courses in CAUTI. This might be related to the fact that the majority of them hold a nursing diploma and all of the nursing books are written in English and they are learning in Arabic. In addition, another causes for a lack of knowledge. This finding agrees with a study was conducted in India by Balu et al. [8] who reported that ranged between 21 to more Köse et al. [9] who found that $(81.7 \%)$ of Istanbul were female. than 30 years age of nurses. In addition, our finding agrees with a study was conducted by Algarni et al. [3] who found 
that more than two-thirds of nurses were female (68.6\%). Moreover, our results agreement with the study by Abdulmalek and Majeed [10] whose found that the highest percentage (51.6\%) of the study participants had a diploma.

The current results agree with the study was conducted by Kose et al. [9] who reported in his study that (53.2\%) had training about CAUTI. Also, it agrees with the study reported by Mukakamanzi [11] who found that (79.2\%) had training on infection control.

Our results this disagreement with other results reported by Opina and Oducado [12] who found that more than half (56.7\%) were males, furthermore more than three-fourths $(76.7 \%)$ had bachelor's degree.

The current study showed that the preventive measures of the catheter-associated urinary tract infection showed that $(72 \%)$ of the nurses knew that antimicrobial prophylaxis offers are not greater benefit in reducing the incidence of CAUTI. This finding disagrees with the study was conducted by Algarni et al. [3] who found that more than half of nurses $(60.6 \%)$ mistakenly considered that antimicrobial prophylaxis offers greater benefit in reducing the incidence of CAUTI.

The current study showed the knowledge level of nurses toward prevention of CAUTI was more than two-third (72\%) of nurses were had fair knowledge might be due to the inadequacy of in-service refreshing training' courses or because hospitals have not a clear and updated guideline protocol that nurses can access and adhere to at work. Our result conformity with study by Tobin et al. [13] the majority, 76.7\% had fair knowledge of CAUTI.

Furthermore, our result of the study accepted with Rashmi and Dhakal [14] who found that, the most $59.37 \%$ of nurses had a moderate level of knowledge and only $16.25 \%$ had an adequate level of knowledge towards the prevention of CAUTI. In the line, the results of our study relative similar with Benny et al. [2] who reported that, majority of nurses $(80.85 \%)$ had fair knowledge on prevention of CAUTI. In the same line, Abdelmoaty et al. [15] who mentioned that, more than half $(54.2 \%)$ of nurses had moderate knowledge regarding prevention methods of CAUTI.

Moreover, this finding is disagreement with the study was conducted in India by Zachariah [16] who reported that more than two third (73\%) of the staff nurses in the pretest were had good knowledge regarding the prevention of urinary tract infections in patients with an indwelling catheter. Furthermore, our study was unaccepted with the study that was conducted by Mukakamanzi [11] who reported that the majority of ICU nurses (64.52\%) have a low level of knowledge regarding CAUTI prevention. On the other hand, Mong et al. [17] who reported that, nurses were found to have good knowledge, a positive attitude and good perceived practice regarding CAUTI prevention. On the line, our result not compatible with Balu et al. [8] who mentioned that, more than one quarter $(28.4 \%)$ of health care professionals had moderately adequate knowledge on CAUTI. Moreover, this result unconformity with Algarni et al. [3] who's revealed that, more than half of nurses $(62.77 \%)$ had a low level of knowledge.

The current study showed there was no statistically significant association 
between overall knowledge and demographic characteristics of nurses regarding age, material statue, educational level, years' experience, and training courses because ( $\mathrm{P}$-value $\geq 0.05$ ). Our result accepted with study by Tobin et al. [13] who mentioned that there was no association between previous training and knowledge of CAUTI prevention. The result of this study disagreed with Rashmi and Dhakal [14] who revealed that, all socio-demographic variables were statistically significant with the level of knowledge about CAUTI prevention.

\section{Conclusions}

Based on the results, we conclude that:

1) More two-thirds of nurses were had fair knowledge regarding preventive of CAUTI, while only (18.3\%) of them had good knowledge.

2) There is a statistically significant difference between knowledge level for preventive measures of CAUTI and demographic characteristics of nurses toward sex only (P-value $=0.042)$.

\section{Recommendations}

Based on the results of the present study, the following can be recommended:

1) Provide written updated guidelines based on evidence to promote urinary catheterization with enough knowledge, and high safe nursing practice to ensure the reduction of the CAUTI rate.

2) Future researchers should compile an evidence-based guideline of CAUTI prevention and catheter care, specifically for nurses.

3) Replication of the study on a larger probability sample acquired from the different geographical areas in a general and private hospitals to figure out the main aspects of these problems.

\section{Acknowledgements}

The authors would like to sincerely thank all those who collaborated in this research, especially the deputy of research of the Public Hospitals at Amran City. We also thank the staff of educational and medical centers and the nurses who participated in this project.

\section{Conflicts of Interest}

The authors declare no conflicts of interest regarding the publication of this paper.

\section{References}

[1] Hartley, S.E. and Valley, S.C. (2015) Prevention of Catheter-Associated Urinary Tract Infections in the Hospital. Hospital Medicine Clinics, 4, 258-271. https://doi.org/10.1016/j.ehmc.2014.11.005

[2] Benny, A.M., Idiculla, A.S., Kunjumon, A. and Sequera, S.K. (2020) Nurses' Knowledge on Prevention of Catheter-Associated Urinary Tract Infection in a Selected 
Hospital of Mangaluru. Journal of Health and Allied Sciences NU, 10, 128-131. https://doi.org/10.1055/s-0040-1716664

[3] Algarni, S.S., Sofar, S.M. and Wazqar, D.Y. (2019) Nurses' Knowledge and Practices toward Prevention of Catheter-Associated Urinary Tract Infection at King Abdulaziz University. Journal of Health, Medicine and Nursing, 14, 50-73.

[4] Anwar, G., Nawaz, G., Afzal, M., Majeed, I. and Waqas, A. (2017) Assessment of Perceptions and Practices of the Nurses to Prevent Indwelling Catheter Associated Infection; Jinnah Hospital Lahore, Pakistan. International Journal of Applied Sciences and Biotechnology, 5, 150-158. https://doi.org/10.3126/ijasbt.v5i2.17317

[5] Jain, M., Dogra, V., Mishra, B., Thakur, A. and Loomba, P.S. (2015) Knowledge and Attitude of Doctors and Nurses Regarding Indication for Catheterization and Prevention of Catheter-Associated Urinary Tract Infection in a Tertiary Care Hospital. Indian Journal of Critical Care Medicine: Peer-Reviewed, 19, 76-81.

https://doi.org/10.4103/0972-5229.151014

[6] Meddings, J., Manojlovich, M., Ameling, J.M., Olmsted, R.N., Rolle, A.J., Greene, M.T., Ratz, D., Snyder, A. and Saint, S. (2019) Quantitative Results of a National Intervention to Prevent Hospital-Acquired Catheter-Associated Urinary Tract Infection: A Pre-Post Observational Study. Annals of Internal Medicine, 171, S38-S44.

[7] Centers for Disease Control and Prevention (2021) Urinary Tract Infection (Catheter-Associated Urinary Tract Infection [CAUTI] and Non-Catheter-Associated Urinary Tract Infection [UTI]) Events. National Healthcare Safety Network, U.S. Hospitals.

[8] Balu, P., Ravikumar, D., Somasunder, V.M., Suga, S.S.D., Sivagnanam, P., Jeyasheelan, V.P., et al. (2021) Assessment of Knowledge, Attitude and Practice on Prevention of Catheter-Associated Urinary Tract Infection (CAUTI) among Health Care Professionals Working in a Tertiary Care Teaching Hospital. Journal of Pure and Applied Microbiology, 15, 335-345. https://doi.org/10.22207/JPAM.15.1.28

[9] Köse, Y., Leblebici, Y., Akdere, S.Ş., Çakmakçı, H., Ötünçtemur, S., Egici M.T. and Bektemür, G. (2016) Level of Knowledge of the Nurses Work in a Public Hospital about the Prevention of Catheter Associated Urinary Tract Infections. SiSli Etfal Hastanesi Tip Bultenil The Medical Bulletin of Sisli Hospital, 50, 70-79. https://doi.org/10.5350/SEMB.20151216103044

[10] Abdulmalek, I.Y. and Majeed, R.A. (2018) Training Program Role in Improving Nurses' Knowledge and Skills of Urethral Catheterization at Maternity Hospital in Duhok City. Journal of Duhok University, 21, 140-153. https://doi.org/10.26682/sjuod.2018.21.2.11

[11] Mukakamanzi, J. (2017) Knowledge, Attitude and Practice of Nurses towards the Prevention of Catheter Associated Urinary Tract Infections in Selected Referral Hospitals in Rwanda. University of Rwanda/College of Medicine and Health Sciences, Butare.

[12] Opina, M.L.F. and Oducado, R.M.F. (2014) Infection Control in the Use of Urethral Catheters: Knowledge and Practices of Nurses in a Private Hospital in Iloilo City. Asia Pacific Journal of Education, Arts and Sciences, 1, 93-100.

[13] Tobin, E.A., Nnadi, C., Ogedegbe, S., Okonofua, M., Akpede, N., Odigie, G., Osagiede, E. and Ukpabio, A. (2021) Prevention of Catheter Associated Urinary Tract Infections: Assessment of Knowledge and Practices among Nurses in a Tertiary Care Centre in Nigeria. International Journal of Infectious Diseases, 101, 274. https://doi.org/10.1016/j.ijid.2020.09.719

[14] Rashmi, K.C. and Dhakal, B. (2021) Knowledge, Attitude and Practice on Preven- 
tion of Catheter-Associated UTI among Nurses of a Tertiary Care Hospital. Journal of College of Medical Sciences-Nepal, 17, 61-68.

[15] Abdelmoaty, A.M., Sabry, H.A., Kenawy, A.M. and Elsebaie, E.H. (2020) Indwelling Urinary Catheter: Effect of Training on Nurses Knowledge and Skills. The Egyptian Family Medicine Journal, 4, 144-157. https://doi.org/10.21608/efmj.2020.90206

[16] Zachariah, C.A. (2016) Effectiveness of SIM on Knowledge \& Practice among Nurses Regarding Prevention of UTI in Patients with Indwelling Catheter. International Journal of Science and Research, 5, 833-836.

[17] Mong, I., Ramoo, V., Ponnampalavanar, S., Chong, M.C. and Wan Nawawi, W. (2021) Knowledge, Attitude, and Practice in Relation to Catheter-Associated Urinary Tract Infection (CAUTI) Prevention: A Cross-Sectional Study. Journal of clinical Nursing. https://doi.org/10.1111/jocn.15899 


\section{Questionnaire}

Part I: Demographic characteristics of Nurses

\section{Please Circle on the correct answer}

No. Statement

Expected answer

1) 22 May Central Teaching Hospital

1. Hospital Name

2) Maternal and Child Hospital

3) National Consultant Hospital

4) Al-Makhathi Hospital

1) Emergency Department

2) Intensive Care Unit

3. Sex

1) Male

2) Female

1) Single

4. Marital status

2) Married

3) Divorcee

4) Dowager

\section{Age (Years)}

\section{Level Education status}

1) Diploma Degree

2) Bachelor's Degree

\section{Years of Experience (Years)}

Do you have training courses in the 1 ) Yes

8. prevention of catheter-associated

$\begin{array}{ll}\text { urinary tract infections? } & \text { 2) No }\end{array}$

\section{Part II: Nurses knowledge regarding preventive of CAUTI

1) Antimicrobial prophylaxis offers greater benefit in reducing the incidence of CAUTI

2) Prophylactic antimicrobials should be given for 3 days when the catheter is inserted

3) Using alcohol hand sanitizer is comparable to hand washing in preventing CAUTI incidence

4) Routine use of antiseptic lubricants to decrease the risk of infection is necessary for urinary catheter insertion

5) Silicone is preferable to Teflon-coated and latex catheter materials in reducing the risk of encrustation for long term catheterized patients who have frequent obstruction

6) Antiseptic meatal cleaning before catheter insertion is necessary for reducing the incidence of Catheter-associated urinary tract infection 


\section{Continued}

7) Removing catheters as early as possible

8) Effective use of Amikacin Sulfate bladder wash as prophylaxis before catheter removal

9) Hand washing should be done immediately before and after any manipulation of the catheter site or apparatus

10) As small a catheter as possible should be used to minimize urethral trauma

11) It should be inserted only when necessary and removed as soon as possible

12) Use of other methods of urinary drainage such as condom catheter drainage, suprapubic or intermittent catheterization for selected patients

13) Avoid kinking of the catheter to maintain an unobstructed flow of urine

14) Irrigation of the bladder with antimicrobial solution/iodine solution at least once daily

15) Twice daily meatal care with an antiseptic solution

16) Collecting bag should be emptied regularly

17) The collecting bag should be kept below the level of the bladder

18) Regular bacteriological monitoring of catheterized patients

19) The catheter should be inserted only by personnel proficient in the technique of aseptic insertion

20) Isolation of patients known to have UTI from other non-infected patients

21) Regular educational training regarding basic urinary catheter care

22) Routinely using antimicrobial coated catheters

\section{Thank you for your participation!!!}

